Eurasian Journal of Business and Economics, 14(27), 29-46, (2021).

\title{
Impact of COVID-19 on Stock Market and Gold Returns in India
}

\author{
Sarika MAHAJAN* ${ }^{*}$ Priya MAHAJAN ${ }^{* *}$
}

Received: September 6, 2020

Revised: April 4, 2021

Accepted: May 5, 2021

\begin{abstract}
The spread of COVID-19 has caused severe damage to human lives and the global economy. The stock markets around the world have plummeted to their lowest levels since the 2008 Global Financial Crisis. This paper attempts to examine the joint dynamics of gold and stock market returns during unprecedented times of health and financial shock due to COVID-19 between January 2020 and May 2020 using granger test, ARMA model, and symmetric and asymmetric GARCH models to improve the understanding of the microstructure of investment scenario in India. The period considered in the study helps to evaluate the impact of lockdown due to coronavirus on Gold and Nifty index return. Results based on GARCH and E-GARCH models indicate a significant negative impact of gold on nifty returns during the sample period. The results also indicate investors' perception of gold as a safe-haven asset during periods of elevated uncertainty. Thus, the study is expected to enhance the understanding of market asymmetry, the behavior of investors towards these avenues of investments, and information processing.
\end{abstract}

Keywords: COVID-19, Lockdown, Stock market return, Volatility, Gold, Information asymmetry

JEL Code Classifications: G11, G15

UDC: 338.31

DOI: https://doi.org/10.17015/ejbe.2021.027.02.

\footnotetext{
*Assistant Professor, Jamnalal Bajaj Institute of Management Studies, University of Mumbai, India, Email: sarikamahajan@jbims.edu

${ }^{* *}$ Assistant Professor, Department of Commerce, Uttarakhand Open University, Haldwani-India, Email: pmahajan@uou.ac.in

Copyright (C), 2021 Ala-Too International University.
} 


\section{Introduction}

The novel coronavirus (COVID-19), which emerged in Wuhan City, Hubei Province of China, spread to other countries over time and was declared a global epidemic by the World Health Organization (WHO) on March 11, 2020. The COVID-19 outbreak is an international pandemic that has taken the world by storm (Yan et al., 2020). The coronavirus has affected 219 countries and territories around the world (WHO, 2020). As per the World Bank's latest assessment, the global economy might hit the worst recession since the Great Depression in the 1930s. COVID - 19 has impacted all financial markets worldwide; particularly, the share prices trend dropped significantly and continuously (Sansa, 2020). India is also no exception to this. With the pandemic, curfews were imposed, workplaces closed, production decreased, shopping stopped, except for basic supplies. WHO (2020) declared that as of May 01, 2020, the total number of confirmed global cases of COVID-19 reached 3,175,207, whereas the total number of deaths was 224,172 (Celebioglu, 2020). COVID-19 endangered human health as well as increased risk perception in financial markets. Large decreases occurred in stock markets in a short time, companies lost value, and stock prices dropped.

India came to terms with Corona Pandemic almost at the end of February, and soon the Stock market bore the brunt of the massive scare that COVID-19 posed, and a big crash ensued, which led to a loss of Rs. 5.3 lakh crores erosion of wealth (Anonymous, 2021). Historically making sense of the market fall, a $3.5 \%$ fall in the market earned it the distinction of being the second-largest fall in the history of the Sensex. With a slight recovery happening on March 02, the markets eventually ended in the red. A week later, on March 09, the markets again saw huge losses by falling over 1900 points in a single intraday session. These Stock market crashes are not new and have happened earlier in the century as well, and during that time, it was gold that turned out to be a saving grace for most investors (Baur \& Lucey, 2010; Baur \& McDermott, 2016; Bouri et al., 2020; Ciner et al., 2010; Ji et al., 2020; Reboredo, 2013)

In the entire world, it does not matter in which country we live or in which country we go; the importance of gold is the same all over the world. When the world economy was hit by the Dotcom Bubble in the year 2000 and during the financial crisis of 2008, it was the investments in gold that performed extremely well during those crises. After the global recession, international gold prices have risen in the last few years, resulting in an accelerated spurt in the gold prices in India (Shiva \& Sethi, 2015). But the current situation due to COVID-19 is much bleaker than a previous global financial crisis. Various studies supported that gold emerged as a safe haven or a hedge in times of market turmoil (Baek, 2019; Pullenet al., 2014; Smirnova, 2016; Le \& Chang, 2011). The safe-haven can broadly be defined as an asset that protects the investor's wealth against market turmoil.

The research of Oxford Economics stated that gold generally does well in the period of deflation. Deflation is when interest rates are low, consumption is going down, 
and there is financial stress in the economy (Rani \& Sharma, 2020). The literature stated that in times of financial crises or financial shocks, gold emerged as an alternative investment asset or an important part of assets in financial portfolios. But in the context of the current pandemic (COVID-19) situation in the country, the study of the relationship between gold prices and the stock market index of an emerging economy like India becomes very interesting. The interest in gold in times of crisis perhaps stems from its historical use as a medium of exchange and standard of value and its stable purchasing power overtimes. Based on this, the current paper attempts to study the joint dynamics of gold and stock market returns during unprecedented times of health and financial shock due to COVID-19 to improve the understanding of the microstructure of the investment scenario in India. The current study tests the following hypothesis using GARCH and EGARCH models ( $\mathrm{HO}$ ): "Lockdown due to coronavirus had no significant impact on the Indian stock market volatility."

Therefore, the current study investigates the gold and stock market returns relationship in India using the granger test, the ARMA model, and the symmetric and asymmetric GARCH models. The current study further contributes to the literature because it examines the impact of lockdown due to COVID-19 on the Indian stock market.

The remainder of the paper is as follows. Section two reviews the literature. In section three, the methodology and data employed are presented. In section four, the key results from the empirical investigation are reported, and in section five, conclusions are drawn.

\section{Review of Literature}

Many studies have been done to investigate the relationship between gold prices and stock indices. Sreekanth and Veni (2014) studied the causal relationship between gold prices and S\&P CNX NIFTY. The data has been taken from 2005 to 2013 for study by using econometric tools like augmented Dickey-Fuller (ADF) test, Johansen co-integration test, VECM, Wald's coefficient diagnosis, residual analysis, and Granger causality test (GCT). The results showed the existence of long-run cointegration between the gold prices and NIFTY. The gold prices and NIFTY were found to be in equilibrium in the short run and long run, and it was found that the gold prices are sufficient to explain the movements of S\&P CNX NIFTY in the short run as well as long run. The GCT confirmed the long-run causality flowing from gold prices to NIFTY.

Gayathri and Dhanabhakyam (2014) tested the causal nexus between the gold prices and Nifty in India for ten years (i.e., 2003-2013). The co-integration test confirmed that there is a co-integration between gold prices and Nifty returns. The GCT confirmed the unidirectional relationship between gold prices and Nifty. When the gold prices of gold change, there is also a change in the stock market indicator NSE Nifty. The studies of Ray (2013), Hemavathy and Gurusamy (2016), Srivastva and Babu (2016), and Patel (2013) also stated that there is co-integration between gold 
prices and Nifty and also unidirectional relationship exist between gold prices and nifty.

On the contrary, the results of Verma and Dhiman (2020) stated that there is no causal relationship between gold prices and Sensex. Granger Causality tests have been applied to study the relationship between gold prices, Sensex, and ETFs. Although there is no causal relationship between gold and Sensex, Gold ETFs are largely affected by the spot price movements of gold. It means the gold prices can help to forecast the daily returns of the maximum gold ETFs under study.

Narang and Singh (2012), based on ten years of data (i.e., 2002-2012), analyzed that there is no long-term co-integration between gold and Sensex, and also no causal nexus exists between gold and Sensex. Mishra (2014) studied the dynamics of the relationship between gold prices and capital market movements from 1978-79 to 2010-2011. The tools like Toda and Yamomota granger non-causality test reported bidirectional causality between gold prices and the BSE 30 Index. It means that both the variables contain some significant information that causes each other.

Some studies also studied the relationship of gold prices with multiple stock indices and other macro-economic variables like the exchange rate of a country's currency, interest rate, inflation rate to examine the relationship among variables. Shiva and Sethi (2015) examined the economic relationship among gold prices, Sensex, Nifty, and exchange rates in India. The monthly data of 15 years period ranging from 1998 to 2014 of the given variables has been studied by applying the econometric tools like Dickey-Fuller Test, Johansen Co-integration test, Wald's co-efficient test, Granger Causality test (GCT). The results stated that there is long-term co-integration among the variables under study. The GCT confirmed the presence of unidirectional causality from gold prices to stock prices and also from gold prices to the USD/INR exchange rate of India. The major implication of the gold market on the Indian economy is that it serves as a type of insurance against extreme movements in the value of traditional assets during an unstable financial market.

Baek (2019) studied the relationship between gold, bond, and the stock market. Johanson co-integration test is applied on past 10-year data of U.S Market to reinvestigate how gold market interacts with the stock market and bond market. The result stated that there is no co-integration between gold returns, bond returns, and market returns. Further Granger causality test is applied, and it stated while there is no co-integration between gold, bond, and market but gold returns have a unidirectional causality with both bond and market returns. Also, it was discovered in the study that gold returns have some predictive power on subsequent short-term stock returns. Under extreme market scenarios, it turns out that gold returns tend to deteriorate more simultaneously with bond returns than stock returns. This means that gold can better serve as a safe haven for stock in a relative sense during temporary market downturns. 
Bhunia (2013) studied the dynamic relationship between crude oil prices, exchange rates, gold prices, and stock price indices of BSE and NSE. Daily data of 20 years from 1991 to 2012 of the given variables have been studied by applying the econometric tools, include the Augmented Dickey-Fuller test, Johansen Co-integration test, Granger Causality Test. The Co-integration test assured the long-term relationship among the selected variables. Further, the results of GCT reported bi-directional causality between gold prices and Nifty, Sensex and gold price, Exchange rate and gold price, Sensex and Nifty. Emmrich and McGroarty (2013) studied the 30 years data sub-divided into the 1980s,1990s, and 2000s of equities, bonds, and various gold instruments included the Gold ETFs entered in the market in 2005. The data of 2000 is further subdivided into the pre-crisis period (financial crisis of 2007\} and postcrisis period. The results stated that the 1980s and 1990s have suggested avoiding gold investing completely. However, data from the 2000s once again provides evidence for including some gold in investment portfolios. The analysis shows that the case for gold investing has become especially strong since the financial crisis in 2007. The research finds that gold bullion almost always produces better portfolio risk-adjusted returns than alternative forms of gold investment.

Bakhsh and Khan (2019) studied the relationship among the variables, i.e., gold prices, crude oil, exchange rate, and stock index of Pakistan, by utilizing the time series data from 1997 to 2018. Statistical techniques like the Dickey-Fuller test, correlation test, Co-integration technique, Granger test have been applied. The results indicated that there is no long-term co-integration among the variables. Whereas stock index and gold prices are highly correlated, but no causal relationship exists between gold and stock index. The results also demonstrate the significant effect of crude oil price $\&$ gold price on the exchange rate.

While the current literature relating the COVID-19 pandemic to financial markets is limited, the existing studies have provided some very interesting results. For example, Corbet et al. (2020) reveal a negative knock-on impact from the coronavirus on some companies with similar names. Also, Akhtaruzzaman et al. (2020) show that listed firms across China and G7 countries have experienced significant increases in the conditional correlations for the market returns. This fact is confirmed by Okorie and Lin (2021), which found considerable fractal contagion on the market return and market volatility. Moreover, Conlon and McGee (2020) and Goodell and Goutte (2021) suggest that cryptocurrencies do not act like safe havens during COVID-19 turmoil.

In a nutshell, based on the above-mentioned studies, it can be stated that little efforts have been made at the international level to evaluate the impact of coronavirus on the stock market and gold return movements, whereas, in India, this relationship has not been well investigated. Therefore, the current study attempts to fill this gap and sheds light on the informational efficiency of the Indian stock market. It contributes to the literature by investigating the gold and stock market relationship during lockdown due to coronavirus news in India. 
This paper examines the relationship between Gold and Nifty index return in a contemporaneous and dynamic context in the Indian stock market and contributes to the literature in several respects. Firstly, it deploys the granger causality test to investigate information flow between the variables along with the ARMA model. Also, we use the GARCH models in the study of the return-volume relationship to examine volatility persistence. This study further checks the information asymmetry with $\operatorname{EGARCH}(1,1)$ model.

Moreover, the ongoing COVID-19 outbreak represents an interesting period to include in our sample because coronavirus lockdowns were initiated throughout the world, increasing the fear of economic loss and stimulating the demand for gold as a safe-haven asset. The period considered in the study helps to evaluate the impact of lockdown due to coronavirus on Gold and Nifty index return. Thus, the study is expected to enhance the understanding of market asymmetry, the behavior of investors towards these avenues of investments, and information processing.

\section{Data Base and Research Methodology}

To investigate the impact exerted by lockdown due to COVID-19 on gold and stock market return, the daily data for gold prices and Nifty closing prices during January 2020 and May 2020 starting from 1/02/2020 to 5/29/2020, have been used in this study. Data has been taken from Bloomberg and verified against data available on NSE and Gold Price India websites. Analysis of data is done using Augmented DickeyFuller (ADF) Test, Correlation test, GARCH $(1,1)$ model, and Bi-variate Granger causality test with the aid of E-Views 8 Software.

\subsection{Methodology}

Two main latent variables for this study are the stock market return and gold return. The daily stock returns are continuous rates of return, computed as a log of the ratio of the present day's price to the previous day's price (i.e., $\mathrm{Rt}=\ln (\mathrm{Pt} / \mathrm{Pt}-1)$ ). Data are obtained from the website of NSE (www.nseindia.com).

Given the nature of time-series data, it is necessary to test the stationarity of each series. One way to test for the existence of unit roots and determine the degree of differencing necessary to induce stationarity is to apply the Augmented Dickey-Fuller (ADF) tests. It consists of regressing the first difference of the series against a constant; the series lagged one period, the differenced series at $\mathrm{n}$ lag lengths, and a time trend (Pindyck \& Rubinfeld, 1998). The model used is as follows:

$$
\Delta r_{t}=\alpha+\sum_{i=1}^{n} \beta_{i} r_{t-1}+\Lambda_{t}+p r_{t-1+\varepsilon_{t}}
$$

Where $t$ is the trend variable, taking values of 1,2 , and so on. Prt-1 is the one period lagged value of the variable $r$. If the coefficient of $p$ is significantly different from zero, then the hypothesis that $r$ is non-stationary is rejected. Unit root test is done with E-views Software, and results are discussed in Table 2. 
It is now a well-known fact that financial return series exhibit strong conditional time-varying volatility, volatility clustering, and volatility persistence. Researchers have introduced various models to explain and predict these patterns in volatility. The most successful empirical workhorse for modeling this characteristic of financial time series is Engle's (1982) Autoregressive Conditional Heteroscedasticity (ARCH) model and its extension, the Generalized Autoregressive Conditional Heteroscedasticity (GARCH) model of Bollerslev (1986). Therefore, this study also used this test with E-views Software while analyzing the impact of the global financial crisis on stock return as well as the volatility of the Indian stock market.

Based on the above logic, the study employs $\mathrm{GARCH}(1,1)$ as a benchmark model to measure the persistence of return volatility. The specifications of the GARCH model are presented below:

Equation (2) specifies the conditional mean equation of the $\operatorname{GARCH}(1,1)$ model.

$$
\begin{aligned}
& R_{t}=\alpha+\beta X_{t}+\varepsilon_{t} \\
& h_{t}=\omega+\sum_{i=1}^{m} \alpha_{i} \varepsilon_{t-1}^{2}+\sum_{j=1}^{n} B_{j} h_{t-j}+e_{t}
\end{aligned}
$$

Equation (2) contains a regress and Rt, in the current study, it is stock return, which depends on $\alpha$ stands for drift term, Xt is/are exogenous variable(s), and $\beta$ is/are coefficient(s) of respective exogenous variable(s). Like other econometric models, $\varepsilon$ t is an error term and subscription; this is denoted for time series data. This equation is generally called the conditional mean equation and is the foremost step for empirical analysis.

Equation (3) is called conditional variance equation, where ht is the conditional volatility, $\alpha i$ is the coefficient of $A R C H$ term with the order $i$ to $m$, and $\beta j$ is the coefficient of GARCH term with order $\mathrm{j}$ ton. The conditional volatility as defined in equation (3) is determined by three effects, namely the intercept term given by $\omega$, the ARCH term expressed by aic2t-i, and the forecasted volatility from the previous period called GARCH component expressed by $\beta$ jht-j. Parameters $\omega$ and $\alpha$ should be higher than 0 , and $\beta$ should be positive to ensure conditional variance ht to be nonnegative. Besides this, it is necessary that $\alpha i+\beta j<1$, which secures covariance stationarity of conditional variance. A straightforward interpretation of the estimated coefficients in equation (3) is that the constant term is the long-term average volatility, whereas $\alpha \mathrm{i}$ and $\beta \mathrm{j}$ represent how volatility is affected by current and past information, respectively. Moreover, the size (magnitude) of parameters $\alpha i$ and $\beta$ j determine the short-run dynamics of the resulting volatility time series. Large $\beta \mathrm{j}$ shows that information shocks to conditional variance take a longer time to die out; thus, volatility persists for longer periods. A large GARCH error coefficient indicates that volatility reacts quite intensely to market movements.

To ascertain the impact of lockdown due to coronavirus on the Indian stock market return volatility, we have run a $\operatorname{GARCH}(1,1)$ estimation using a dummy variable in the variance equation. A dummy variable (Dt) takes a value of 1 for the daily returns 
of March 21, 2020 to May 29, 2020 defined as lockdown period otherwise 0 . If the coefficient of the dummy is statistically significant, then the lockdown due to coronavirus has an impact on the stock market volatility. A significant positive coefficient would indicate an increase in volatility; a significant negative co-efficient would indicate a decrease in volatility.

Also, other diagnostic tests are also considered to finalize the model for empirical analysis. Finally, the following mean and modified variance equation depicting the influence of lockdown due to pandemic are as follows:

$$
\begin{aligned}
& R_{t}=\alpha+\varepsilon t \\
& h_{t}=\omega+\sum_{i=1}^{m} \alpha_{i} \varepsilon_{t-1}^{2}+\sum_{j=1}^{n} B_{j} h_{t-j}+\gamma D_{t}+e_{t}
\end{aligned}
$$

Conditional variance equation 5 contains dummy variable (Dt) of lockdown due to pandemic to ascertain its effect on the stock market volatility in India.

However, the results based upon GARCH $(1,1)$ may again be doubtful because it does not take into account asymmetry and non-linearity in the conditional variance. Thus, it would be more appropriate to apply the asymmetric GARCH model. Engle and $\mathrm{Ng}$ (1993) developed an asymmetric GARCH model, which allows for asymmetric shocks to volatility. Thus, among the specifications, which allow for asymmetric shocks to volatility, we estimate the $\operatorname{EGARCH}(1,1)$ or exponential $\operatorname{GARCH}(1,1)$ model, which was proposed by Nelson (1991), and results are reported in Table 10.

$$
h_{t}=\gamma_{1}+\gamma_{2}\left|\frac{\varepsilon_{t-1}}{h_{t-1}}\right|+\gamma_{3} \frac{\varepsilon_{t-1}}{h_{t-1}}+\gamma_{4} h_{t-1}+e_{t}
$$

In this model specification, $\gamma 2$ is the ARCH term that measures the effect of news about volatility from the previous period on current period volatility. $\gamma 3$ measures the leverage effect. Ideally, $\gamma 3$ is expected to be negative, implying that bad news has a bigger impact on volatility than the good news of the same magnitude. $A$ positive $\gamma 4$ indicates volatility clustering implying that positive stock price changes are associated with further positive changes and vice-versa. The parameter $\mathrm{\gamma} 5$ or $\mathrm{C7}$ (see table 10) measures the impact of volume on volatility.

\section{Data Analysis and Empirical Findings}

This paper begins the empirical analysis by first presenting the descriptive statistics of price and return series of Gold spot and NIFTY to check the normality of series. Table 1 provides the sample descriptive statistics, which provides important information regarding the behavior of Indian stock market return and gold returns during ongoing COVID-19 health and financial turmoil.

The data employed in this study comprise daily closing spot prices for gold and nifty index. For both price series, the natural logarithms are taken, and each return series is calculated as follows: $r t 1 / 4\{\ln (y t) \ln (y t 1)\} 100$, where yt is the gold price or the Nifty index. As illustrated in Figure 1, gold price was almost monotonically increasing except for some short-term declines during the sample period; consequently, the 
mean gold return is positive (0.001). This graph also indicates that non-normality exists in the series as confirmed from statistical analysis, and inertia of volatility clustering also prevails in the markets. Table 1 reports the descriptive statistics of the price and returns on gold and the Nifty index.
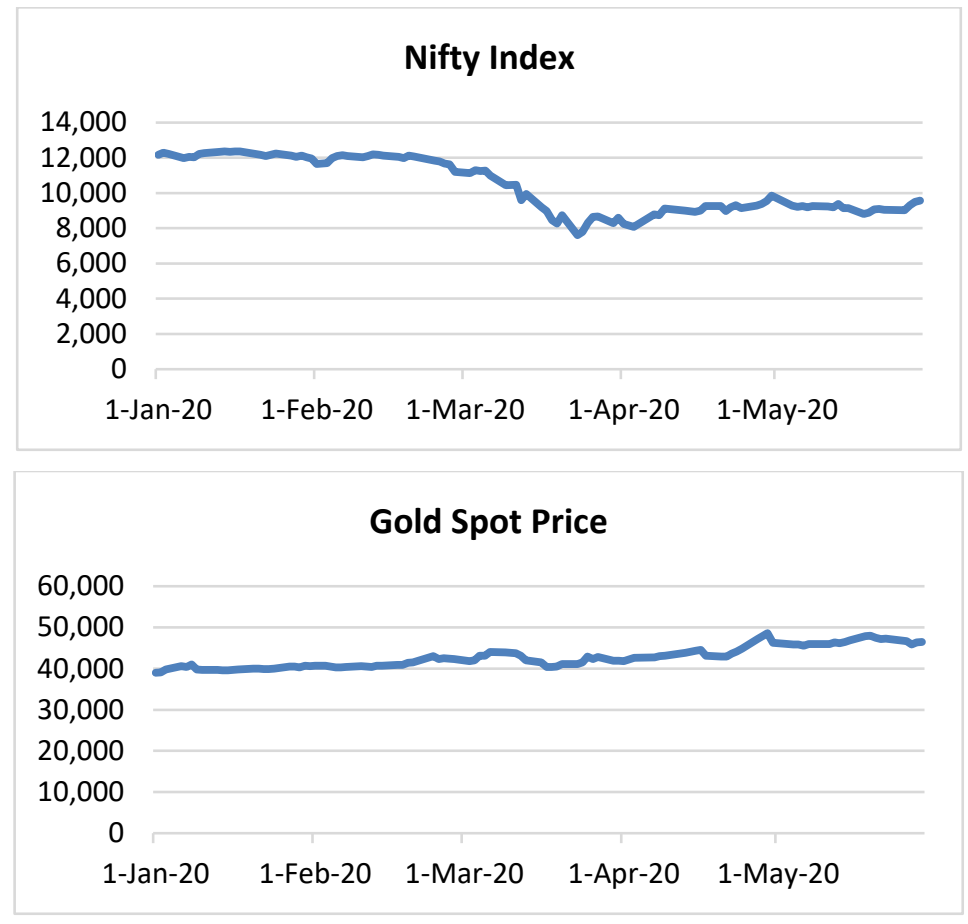

Figure 1. Gold price and the Nifty index

The current study presents an analysis of descriptive statistics in Table 1 for the price and returns series of gold spot and nifty index, where price denoted $P t$, and returns, denoted $R t$, for the sample. The gold price series show positive skewness coefficients, indicating a right-skewed distribution, while the return series of gold and nifty index demonstrates a negative skewness coefficient with a left-skewed distribution. Furthermore, a leptokurtic distribution can be deduced from the excess kurtosis values for the prices and returns of the two series.

While the mean Nifty index return is negative (0.001), it is essentially zero and more volatile than the gold market (the SD is 0.014 for the gold return and 0.028 for the Nifty index return). In this sense, gold is a safer asset class relative to stocks during this unprecedented time of COVID-19, which has created health and economic shock for the economy. Kurtosis exhibits a leptokurtic distribution. As clearly shown by the Jarque-Bera test statistic and its $p$-value, the price and return series of both the gold and Nifty index return are not normal at the $1 \%$ significance level. 
Sarika MAHAJAN \& Priya MAHAJAN

Table 1. Descriptive Statistics

\begin{tabular}{lcccc}
\hline & NIFTY_PRICES & GOLD_PRICES & GOLD_RETURNS & NIFTY_RETURNS \\
\hline Mean & 10442.03 & 42657.11 & 0.001844 & -0.001989 \\
\hline Median & 9955.200 & 42009.00 & 0.001108 & -0.001229 \\
\hline Maximum & 12362.30 & 48600.00 & 0.053336 & 0.087632 \\
\hline Minimum & 7610.250 & 38977.00 & -0.047325 & -0.129805 \\
\hline Std. Dev. & 1537.566 & 2587.914 & 0.014030 & 0.028508 \\
\hline Skewness & -0.028588 & 0.629270 & -0.013115 & -0.873919 \\
\hline Kurtosis & 1.322284 & 2.174339 & 5.703552 & 7.575974 \\
\hline Jarque-Bera & 11.85908 & 9.534559 & 30.45784 & 99.97699 \\
\hline Probability & 0.002660 & 0.008503 & 0.000000 & 0.000000 \\
\hline
\end{tabular}

The ADF test results have been exhibited in Tables 2 and Table 3 for return level data or the first differenced price series of gold and nifty, respectively. Entire calculations are made in Schwarz information criteria (SIC) with the maximum lag length (MAXLAG) criteria of 12 lags in Tables 2 and 3. It is found that gold returns and nifty returns series are stationary with $p$-values of 0.0000 , and therefore, the data are fit enough to apply Granger causality, VAR, and other tests. In other words, the return series have no unit-roots. Hence, the level form of returns will be used for further estimation throughout the analysis, not the price series of gold and Nifty index.

\section{Table 2. Stationarity Test for Unit Root for Nifty Returns}

Null Hypothesis: NIFTY_RETURNS has a unit root

\section{Exogenous: Constant}

Lag Length: 0 (Automatic - based on SIC, maxlag=12)

\begin{tabular}{lccc}
\hline & & t-Statistic & Prob. $^{*}$ \\
\hline Augmented Dickey-Fuller test statistic & -11.78955 & 0.0001 \\
\hline Test critical values: & 1\% level & -3.497727 & \\
\hline & $5 \%$ level & -2.890926 & \\
\hline
\end{tabular}

*MacKinnon (1996) one-sided p-values.

\section{Table 3. Stationarity Test for Unit Root for Gold Returns}

Null Hypothesis: GOLD_RETURNS has a unit root

\section{Exogenous: Constant}

Lag Length: 0 (Automatic - based on SIC, maxlag=12)

\begin{tabular}{lccc}
\hline & & t-Statistic & Prob. $^{*}$ \\
\hline Augmented Dickey-Fuller test statistic & -8.993060 & 0.0000 \\
\hline Test critical values: & 1\% level & -3.497727 & \\
\hline & $5 \%$ level & -2.890926 & \\
\hline & $10 \%$ level & -2.582514 & \\
\hline
\end{tabular}

*MacKinnon (1996) one-sided p-values. 


\section{Table 4. Granger Causality Test}

Pairwise Granger Causality Tests

Date: 07/31/20 Time: 13:53

Sample: 1101

Lags: 2

Null Hypothesis:

\begin{tabular}{lll}
98 & 0.19081 & 0.8266 \\
\hline & 3.62000* & 0.0306 \\
\hline
\end{tabular}

NIFTY_RETURNS does not Granger Cause GOLD_RETURNS

Note: ${ }^{*}$ denote for significant at $5 \%$ level.

The Granger-Causality test results reveal that unidirectional causality running from the gold returns to the Nifty returns, whereas the reverse is not true. The granger causality is further supported by VAR results in Table 5 where we can see lagged gold returns cause Nifty returns. These findings inevitably suggest that the gold price contains some significant information to forecast Nifty return.

\section{Table 5. VAR results}

\begin{tabular}{|c|c|c|}
\hline \multicolumn{3}{|c|}{ Vector Autoregression Estimates } \\
\hline \multicolumn{3}{|c|}{ Date: 07/31/20 Time: $16: 45$} \\
\hline \multicolumn{3}{|c|}{ Sample (adjusted): 2100} \\
\hline \multicolumn{3}{|c|}{ Included observations: 99 after adjustments } \\
\hline \multicolumn{3}{|c|}{ Standard errors in ( ) \& t-statistics in [ ] } \\
\hline & GOLD_RETURNS & NIFTY_RETURNS \\
\hline \multirow{3}{*}{ GOLD_RETURNS(-1) } & 0.089660 & 0.415162 \\
\hline & $(0.10144)$ & $(0.19953)$ \\
\hline & {$[0.88386]$} & [ 2.08074] \\
\hline \multirow{3}{*}{ NIFTY_RETURNS(-1) } & 0.032056 & -0.181036 \\
\hline & $(0.04996)$ & $(0.09827)$ \\
\hline & [0.64163] & {$[-1.84228]$} \\
\hline \multirow{3}{*}{ C } & 0.001749 & -0.003245 \\
\hline & $(0.00144)$ & $(0.00283)$ \\
\hline & [ 1.21471$]$ & {$[-1.14629]$} \\
\hline R-squared & 0.012440 & 0.073501 \\
\hline Adj. R-squared & -0.008134 & 0.054199 \\
\hline Sum sq. resids & 0.019243 & 0.074446 \\
\hline S.E. equation & 0.014158 & 0.027847 \\
\hline F-statistic & 0.604646 & 3.807919 \\
\hline Log likelihood & 282.5377 & 215.5688 \\
\hline Akaike AIC & -5.647226 & -4.294319 \\
\hline Schwarz SC & -5.568586 & -4.215679 \\
\hline Mean dependent & 0.001848 & -0.002092 \\
\hline S.D. dependent & 0.014101 & 0.028634 \\
\hline \multicolumn{2}{|c|}{ Determinant resid covariance (dof adj.) } & $1.55 \mathrm{E}-07$ \\
\hline \multicolumn{2}{|c|}{ Determinant resid covariance } & $1.46 \mathrm{E}-07$ \\
\hline \multicolumn{2}{|l|}{$\underline{\text { Log likelihood }}$} & 498.1094 \\
\hline \multicolumn{2}{|c|}{ Akaike information criterion } & -9.941604 \\
\hline \multicolumn{2}{|l|}{ Schwarz criterion } & -9.784324 \\
\hline
\end{tabular}


After examining the dynamic relationship between gold and the nifty index, it is imperative to check the dependence of nifty returns on gold. So, further, we have applied the ARMA model $(2,2)$ to see the impact of gold on the Nifty index and to see the impact of fear and panic created by lockdown due to COVID-19 using a dummy variable for the lockdown period, where (Dt) takes a value of 1 for the daily returns of March 21, 2020 to May 29, 2020 defined as lockdown period otherwise 0.

Results in Table 5 indicate that Nifty index returns are greatly impacted by the lockdown period due to COVID-19. Whereas in the ARMA model $(2,2)$, the impact of gold on the Nifty index is not significant. It is mandatory to check certain conditions while running ARMA modeling. So, the current study has applied the BreuschGodfrey Serial Correlation LM Test to see serial correlation data and found no serial correlation in our data set (Table 7). But we found the ARCH effect in our data while running the ARMA model (Table 8 ). So, the results of the ARMA $(2,2)$ model may be spurious as the ARCH effect is there. And, it is very much established in literature to go for GARCH modeling when there is an ARCH effect in data.

\section{Table 6. ARMA $(2,2)$ Model with a dummy variable for Lockdown period}

\begin{tabular}{|c|c|c|c|c|}
\hline \multicolumn{5}{|c|}{ Dependent Variable: NIFTY_RETURNS } \\
\hline \multicolumn{5}{|l|}{ Method: Least Squares } \\
\hline \multicolumn{5}{|c|}{ Date: 07/31/20 Time: 17:31 } \\
\hline \multicolumn{5}{|c|}{ Sample (adjusted): 3100} \\
\hline \multicolumn{5}{|c|}{ Included observations: 98 after adjustments } \\
\hline \multicolumn{5}{|c|}{ Convergence achieved after 32 iterations } \\
\hline \multicolumn{5}{|l|}{ MA Backcast: 12} \\
\hline Variable & Coefficient & Std. Error & t-Statistic & Prob. \\
\hline C & -0.030643 & 0.017193 & -1.782274 & 0.0780 \\
\hline GOLD_RETURNS & 0.129802 & 0.156187 & 0.831068 & 0.4081 \\
\hline DUMMY & 0.040962 & 0.011193 & 3.659512 & 0.0004 \\
\hline $\mathrm{AR}(1)$ & 1.324055 & 0.157875 & 8.386713 & 0.0000 \\
\hline $\mathrm{AR}(2)$ & -0.347000 & 0.154928 & -2.239745 & 0.0275 \\
\hline $\mathrm{MA}(1)$ & -1.713632 & 0.108405 & -15.80771 & 0.0000 \\
\hline $\mathrm{MA}(2)$ & 0.809364 & 0.111045 & 7.288589 & 0.0000 \\
\hline R-squared & 0.152141 & \multicolumn{2}{|c|}{ Mean dependent var } & -0.002067 \\
\hline Adjusted R-squared & 0.096238 & \multicolumn{2}{|c|}{ S.D. dependent var } & 0.028780 \\
\hline S.E. of regression & 0.027360 & \multicolumn{2}{|c|}{ Akaike info criterion } & -4.290688 \\
\hline Sum squared resid & 0.068122 & \multicolumn{2}{|c|}{ Schwarz criterion } & -4.106048 \\
\hline Log likelihood & 217.2437 & \multicolumn{2}{|c|}{ Hannan-Quinn criterion } & -4.216005 \\
\hline F-statistic & 2.721529 & \multicolumn{2}{|c|}{ Durbin-Watson stat } & 1.992277 \\
\hline Prob(F-statistic) & \multicolumn{3}{|l|}{0.017758} & \\
\hline Inverted AR Roots & .96 & \multicolumn{2}{|l|}{.36} & \\
\hline Inverted MA Roots & $.86-.27 i$ & \multicolumn{2}{|l|}{$.86+.27 i$} & \\
\hline
\end{tabular}

To meet the objectives of this study, the GARCH model is used based on conditional mean and variance equations. The results of the $\operatorname{GRACH}(1,1)$ model, along with the dummy variable for the lockdown period, are presented in Table 9 . The results of the 
mean equation of the GARCH model confirm that gold has a significant impact on the Nifty return as the coefficient of gold returns is negative and significant.

Table 7. Breusch-Godfrey Serial Correlation LM Test for ARMA $(2,2)$ model

\begin{tabular}{llll}
\hline $\mathrm{H}_{\mathrm{o}}$ : There is no serial correlation in data & & \\
\hline F-statistic & 0.021253 & Prob. $\mathrm{F}(2,89)$ & 0.9790 \\
\hline Obs*R-squared & 0.046074 & Prob. Chi-Square(2) & 0.9772 \\
\hline
\end{tabular}

Table 8. Heteroskedasticity Test: ARCH for ARMA $(2,2)$ Model

\begin{tabular}{llll}
\hline F-statistic & 10.05611 & Prob. F(1,95) & 0.0020 \\
\hline Obs*R-squared & 9.284967 & Prob. Chi-Square(1) & 0.0023 \\
\hline
\end{tabular}

Table 9. GARCH $(1,1)$ Model with a dummy variable for lockdown period due to COVID -19

\begin{tabular}{|c|c|c|c|c|}
\hline \multicolumn{5}{|c|}{ Dependent Variable: NIFTY_RETURNS } \\
\hline \multicolumn{5}{|c|}{ Method: ML - ARCH (Marquardt) - Normal distribution } \\
\hline \multicolumn{5}{|c|}{ Date: 07/31/20 Time: $17: 38$} \\
\hline \multicolumn{5}{|c|}{ Sample (adjusted): 1100} \\
\hline \multicolumn{5}{|c|}{ Included observations: 100 after adjustments } \\
\hline \multicolumn{5}{|c|}{ Convergence achieved after 30 iterations } \\
\hline \multicolumn{5}{|c|}{ Presample variance: backcast (parameter $=0.7$ ) } \\
\hline \multicolumn{5}{|c|}{ GARCH $=\mathrm{C}(3)+\mathrm{C}(4) * \mathrm{RESID}(-1)^{\wedge} 2+\mathrm{C}(5)^{*} \mathrm{GARCH}(-1)+\mathrm{C}(6) * \mathrm{DUMMY}$} \\
\hline Variable & Coefficient & Std. Error & z-Statistic & Prob. \\
\hline $\mathrm{C}$ & 0.001391 & 0.001255 & 1.108774 & 0.2675 \\
\hline GOLD_RETURNS & -0.510401 & 0.125245 & -4.075236 & 0.0000 \\
\hline \multicolumn{5}{|c|}{ Variance Equation } \\
\hline C & $6.80 \mathrm{E}-06$ & $5.89 \mathrm{E}-06$ & 1.154920 & 0.2481 \\
\hline $\operatorname{RESID}(-1)^{\wedge} 2$ & 0.389459 & 0.150111 & 2.594465 & 0.0095 \\
\hline GARCH(-1) & 0.724345 & 0.104759 & 6.914384 & 0.0000 \\
\hline DUMMY & $-1.22 \mathrm{E}-05$ & $4.28 \mathrm{E}-05$ & -0.284150 & 0.7763 \\
\hline R-squared & -0.077396 & \multicolumn{2}{|c|}{ Mean dependent var } & -0.001989 \\
\hline Adjusted R-squared & -0.088390 & \multicolumn{2}{|c|}{ S.D. dependent var } & 0.028508 \\
\hline S.E. of regression & 0.029741 & \multicolumn{2}{|c|}{ Akaike info criterion } & -4.908161 \\
\hline Sum squared resid & 0.086683 & \multicolumn{2}{|c|}{ Schwarz criterion } & -4.751851 \\
\hline Log likelihood & 251.4081 & \multicolumn{2}{|c|}{ Hannan-Quinn criterion } & -4.844900 \\
\hline Durbin-Watson stat & 2.178316 & & & \\
\hline
\end{tabular}

As far as the conditional variance equation is concerned, the study finds parameters $\alpha i(A R C H)$ and $\beta j(G A R C H)$ positive and significant in Table 10. It indicates that conditional variance is predominantly affected by lagged variance (volatility clustering), which implies that previous information shock significantly affects current returns. Volatility clustering suggests that movement in price variance once initiated tends to persist over the period and steadily declines. Large $\beta \mathrm{j}$ shows that shocks to conditional variance take a long time to die out. Thus, volatility is persistent. The last coefficient of this model is concerned with the recent lockdown due to the COVID-19 health crisis, which has a negative impact, but its effect is 
insignificant due to asymmetric information, which cannot be captured by the GARCH model.

As significant asymmetry is observed in the returns of the Nifty index, thus it would be more informative if we examine the gold and Nifty returns relationship through EGARCH $(1,1)$ model to take into account the impact of good and bad news on the volatility knowing the fact that both types of news have different kinds of effect on the market. The results of EGARCH $(1,1)$ are shown in Table 10.

\section{Table 10. EGARCH Model Estimates with a dummy variable for lockdown period due to COVID-19}

\begin{tabular}{|c|c|c|c|c|}
\hline \multicolumn{5}{|c|}{ Dependent Variable: NIFTY_RETURNS } \\
\hline \multicolumn{5}{|c|}{ Method: ML - ARCH (Marquardt) - Normal distribution } \\
\hline \multicolumn{5}{|c|}{ Date: $07 / 31 / 20$ Time: $17: 36$} \\
\hline \multicolumn{5}{|l|}{ Sample (adjusted): 1100} \\
\hline \multicolumn{5}{|c|}{ Included observations: 100 after adjustments } \\
\hline \multicolumn{5}{|c|}{ Convergence achieved after 20 iterations } \\
\hline \multicolumn{5}{|c|}{ Presample variance: backcast (parameter $=0.7$ ) } \\
\hline \multicolumn{5}{|c|}{ LOG(GARCH) = C(3) + C(4)*ABS(RESID(-1)/@SQRT(GARCH(-1))) + C(5) } \\
\hline \multicolumn{5}{|c|}{${ }^{*}$ RESID(-1)/@SQRT(GARCH(-1)) + C(6)*LOG(GARCH(-1)) + C(7) } \\
\hline \multicolumn{5}{|l|}{ *DUMMY } \\
\hline Variable & Coefficient & Std. Error & z-Statistic & Prob. \\
\hline $\mathrm{C}$ & -0.000420 & 0.001092 & -0.384382 & 0.7007 \\
\hline GOLD_RETURNS & -0.463439 & 0.124038 & -3.736273 & 0.0002 \\
\hline \multicolumn{5}{|c|}{ Variance Equation } \\
\hline$C(3)$ & 0.216955 & $6.53 \mathrm{E}-05$ & 3324.930 & 0.0000 \\
\hline$C(4)$ & -0.110146 & $6.17 \mathrm{E}-07$ & -178487.8 & 0.0000 \\
\hline$C(5)$ & -0.226960 & 0.043879 & -5.172467 & 0.0000 \\
\hline$C(6)$ & 1.008937 & 0.002329 & 433.2318 & 0.0000 \\
\hline$C(7)$ & -0.135171 & 0.025557 & -5.288957 & 0.0000 \\
\hline R-squared & -0.058925 & Mean depende & & -0.001989 \\
\hline Adjusted R-squared & -0.069730 & S.D. dependen & & 0.028508 \\
\hline S.E. of regression & 0.029485 & Akaike info crit & & -5.164405 \\
\hline Sum squared resid & 0.085197 & Schwarz criteri & & -4.982043 \\
\hline Log likelihood & 265.2203 & Hannan-Quinn & rion & -5.090600 \\
\hline Durbin-Watson stat & 2.207763 & & & \\
\hline
\end{tabular}

The presence of the leverage effect can be seen in Table 10, which implies that every price change responds asymmetrically to the positive and negative news in the market. The coefficient of gold returns shows a significant negative impact on nifty return. The parameter $\mathrm{C}(4)$ is statistically significant, which supports the previous evidence of asymmetric distribution of returns in descriptive statistics. The significant $C(5)$ parameter indicates the mean-reverting behavior of returns because the value of $C(5)$ is negative, which implies that every price change responds asymmetrically to the positive and negative news in the market. Coefficient $C(6)$, a parameter of lagged conditional volatility, is significant, which implies that the Indian 
market is informationally inefficient. Coefficient $\mathrm{C}(7)$, a parameter of lockdown period dummy, is statistically significant and negative, which implies that closure of activities of service and industrial sector because of lockdown by the central government in India to control the spread of COVID-19 have impacted volatility or increased volatility in Indian stock market.

This evidence confirms that the recent lockdown due to COVID-19 positively hit the volatility of stock return. The above discussion suggests increased volatility of the Indian stock-return series during the lockdown period. It might be due to the loss of confidence of domestic investors in the market because of uncertainty created by financial and health shock due to COVID-19. And, this uncertainty during lockdown due to COVID-19 has attracted investors again towards gold investment, which further increased demand and has pushed its rate to the higher side.

\section{Conclusion}

One of the major characteristics of safe-haven assets is that the return on these assets should have a zero or negative beta with stock market returns during turmoil periods. Results obtained from this study showed that gold had positive returns during the lockdown period due to the Coronavirus pandemic, indicating that they can be labeled as safe-haven assets, but these returns were not caused by stock markets' negative returns rather by other variables. So, we can say here that panic and fear created in lockdown have directed investors towards the gold market. Also, we can see from the results of linear Granger causality and VAR tests that lagged gold returns cause Nifty returns. These findings inevitably suggest that the gold price contains some significant information to forecast Nifty return.

This study offers novel empirical evidence on the relationship between Gold and Nifty index return during lockdown due to COVID-19 related news. Results based on GARCH and E-GARCH models indicate a significant negative impact of gold on nifty returns during the sample period. The results also indicate investors' perception of gold as a safe-haven asset during periods of elevated uncertainty.

Dummy variable used in ARMA and EGARCH models to examine the impact of lockdown due to pandemic on stock market return and volatility is significant, thereby shows how health shock has created financial turmoil in the market and closure of activities of service and industrial sector because of lockdown by the central government in India to control the spread of COVID-19 have increased volatility in Indian stock market.

\section{References}

Akhtaruzzaman, M., Boubaker, S., \& Sensoy, A. (2021). Financial contagion during COVID-19 crisis. Finance Research Letters, 38, 101604. https://doi.org/10.1016/j.frl.2020.101604

Anonymous (2021, February 26). Market crash wipes off ₹5.3 lakh crore of investor wealth. Mint. https://www.livemint.com/market/stock-market-news/market-crash-wipes-off-5-3lakh-crore-of-investor-wealth-11614343660124.html 
Baek, C. (2019). How are gold returns related to stock or bond returns in the U.S. market? Evidence from the past 10-year gold market, Applied Economics, 59, 347-370. https://doi.org/10.1080/00036846.2019.1616062

Bakhsh, R. P., \& Khan, B. (2019). Interdependencies of Stock Index, Oil Price, Gold Price and Exchange Rate: A Case Study of Pakistan. International Journal of Experiential Learning \& Case Studies, 4(2), 316-331.

Baur D.G., \& Lucey B.M. (2010). Is gold a hedge or a safe haven? An analysis of stocks, bonds, and gold, Financial Review, 45, 217-229. https://doi.org/10.1111/j.1540-6288.2010.00244.x

Baur, D.G. \& McDermott, T.K. (2016). Why is gold a safe haven?. Journal of Behavioral and Experimental Finance, 10, 63-71. https://doi.org/10.1016/j.jbef.2016.03.002

Bhunia, A. (2013). Cointegration and causal relationship among crude price, domestic gold price and financial variables: an evidence of BSE and NSE. Journal of Contemporary Issues in Business Research, 2(1), 1-10.

Bollerslev, T., (1986). Generalized Autoregressive Conditional Heteroscedasticity, Journal of Econometrics, 31, 307-327. https://doi.org/10.1016/0304-4076(86)90063-1

Bouri, E., Shahzad, S. J. H., Roubaud, D., Kristoufek, L., \& Lucey, B. (2020). Bitcoin, gold, and commodities as safe havens for stocks: New insight through wavelet analysis. The Quarterly Review of Economics and Finance, 77, 156-164. https://doi.org/10.1016/i.qref.2020.03.004

Celebioglu, F. (2020). Spatial Spillover Effects of Mega-City Lockdown Due to Covid-19 Outbreak: Evidence from Turkey. Eurasian Journal of Business and Economics, 13(26), 93-108. https://doi.org/10.17015/ejbe.2020.026.05

Ciner, C., Gurdgiev, C., \& Lucey B.M. (2010). Hedges and safe havens: An examination of stocks, bonds, gold, oil and exchange rates, International Review of Financial Analysis, 29, 202-211 https://doi.org/10.1016/j.irfa.2012.12.001

Conlon, T., \& McGee, R. (2020). Safe haven or risky hazard? Bitcoin during the COVID-19 bear market. Finance Research Letters, 35, 101607. https://doi.org/10.1016/j.frl.2020.101607

Corbet, S., Larkin, C., \& Lucey, B. (2020). The contagion effects of the COVID-19 pandemic: Evidence from Gold and Cryptocurrencies, Finance Research Letters, 35, 101554. https://doi.org/10.1016/i.frl.2020.101554

Emmrich, O., \& McGroarty, F. J. (2013). Should gold be included in institutional investment portfolios?. Applied Financial Economics, 23(19), 1553-1565. https://doi.org/10.1080/09603107.2013.839858

Engle, R., (1982). Autoregressive Conditional Heteroskedasticity with Estimates of United Kingdom Inflation, Econometrica, 50, 987-1008. https://doi.org/10.2307/1912773

Engle, R.F. \& Ng, V.K. (1993). Measuring and Testing the Impact of News on Volatility, Journal of Finance, 48, 1749-1778. https://doi.org/10.1111/j.1540-6261.1993.tb05127.x

Gayathri, V., \& Dhanabhakyam, M. (2014). Cointegration and Causal Relationship between Gold Price and Nifty-An Empirical Study, Abhinav International Monthly Refereed Journal of Research in Management \& Technology, 3(7), 14-21.

Goodell, J. W., \& Goutte, S. (2021). Diversifying equity with cryptocurrencies during COVID19. International Review of Financial Analysis, 76, 101781. https://doi.org/10.1016/j.irfa.2021.101781

Granger, C. W. J \& Morgernstern, O. (1963). Spectral Analysis of New York Stock Market Prices, Kyklos, 16(1), 1-27. https://doi.org/10.1111/j.1467-6435.1963.tb00270.x 
Hemavathy, P., \& Gurusamy, S. (2016). Testing the causality and co integration of gold price and NSE (S\&P CNX NIFTY): Evidence from India. Amity Global Business Review, 2(1), 55-71.

Ji, Q., Zhang, D., \& Zhao, Y. (2020). Searching for safe-haven assets during the COVID-19 pandemic. International Review of Financial Analysis, 71, 101526 https://doi.org/10.1016/j.irfa.2020.101526

Le, T., \& Chang, Y. (2011). Dynamic relationships between the price of oil, gold and financial variables in Japan: A bounds testing approach (MPRA Paper No 33030). https://mpra.ub.unimuenchen.de/id/eprint/33030.

Mishra, P.K. (2014). Gold price and capital market movement in India: The Toda-Yamamoto approach, Global Business Review, 15(1), 37-45. https://doi.org/10.1177/0972150913515597

Narang, S. P., \& Singh, R. P. (2012). Causal relationship between gold price and Sensex: A study in Indian context. Vivekananda Journal of Research, 1(1), 33-37.

Nelson, D.B., (1991). Conditional Heteroskedasticity in Asset Returns: A New Approach, Econometrica, 59(2), 347. https://doi.org/10.2307/2938260

Okorie, D. I., \& Lin, B. (2021). Stock markets and the COVID-19 fractal contagion effects. Finance Research Letters, 38, 101640. https://doi.org/10.1016/i.frl.2020.101640

Patel, S. A. (2013). Dynamic Linkages of Developed Equity Markets with Indian Stock Market. Vilakshan: The XIMB Journal of Management, 10(1), 21-36.

Pindyck, S.R. \& Rubinfeld, L.D. (1998). Econometric Models and Economic Forecasts. Irwin/McGraw-Hill, New York.

Pullen, T., Benson, K., \& Faff, R. (2014). A comparative analysis of the investment characteristics of alternative gold assets. Abacus, 50(1), 76-92. https://doi.org/10.1111/abac.12023

Rani, N. \& Sharma, A. (2020, May 20). Is it safe to make investments in gold at this point? Economic Times. https://economictimes.indiatimes.com/mf/analysis/is-it-safe-to-makeinvestments-in-gold-at-this-point/articleshow/75839421.cms

Ray, S. (2013). Causal nexus between gold price movement and stock market: Evidence from Indian stock market, Econometrics, 1(1), 12-19.

Reboredo, J.C. (2013). Is gold a safe haven or a hedge for the US dollar? Implications for risk management, Journal of Banking \& Finance, 37(8), 2665-2676. https://doi.org/10.1016/i.jbankfin.2013.03.020

Sansa, N. A. (2020). The Impact of the COVID-19 on the Financial Markets: Evidence from China and USA. Electronic Research Journal of Social Sciences and Humanities, 2(II) https://doi.org/10.2139/ssrn.3567901

Shiva, A., \& Sethi, M. (2015). Understanding dynamic relationship among gold price, exchange rate and stock markets: Evidence in Indian context. Global Business Review, 16(5_suppl), 93S111S. https://doi.org/10.1177/0972150915601257

Smirnova, E. (2016). Use of gold in financial risk hedge, Quarterly Journal of Finance \& Accounting, 54(1/2), 69-100.

Sreekanth, D., \& Veni, L.K. (2014). Causal relationship between gold price and S\&P CNX NIFTYAn empirical study in Indian context, Asian Journal of Research in Banking and Finance, 4(5), 253-265.

Srivastava, M. A., \& Babu, S. H. (2016). Causal Relation Between Gold and Stock Returns in India: A Study. Research Journal of Social Science and Management, 6, 1-11. 
Verma, R., \& Dhiman, D. (2020). A causal study on gold, SENSEX, and gold exchange traded funds. Gold Bulletin, 53, 121-128. https://doi.org/10.1007/s13404-020-00280-3

WHO (2020). WHO Coronavirus Disease (COVID-19) Dashboard. 2020.

Yan, B., Stuart, L., Tu, A., \& Zhang, T. (2020). Analysis of the Effect of COVID-19 on the stock market and investing strategies. Available at SSRN 3563380. https://ssrn.com/abstract=3563380. 